\title{
Earthworm Abundance and Soil Characteristics Following Cocoa Waste and Manure Applications
}

\author{
Erwin Prastowo $^{1)}$, Lina Dwi Agustina ${ }^{2}$, and Cahyo Prayogo ${ }^{2)}$ \\ ${ }^{1}$ Indonesian Coffee and Cocoa Research Institute, Jl. PB. Sudirman No. 90, Jember, Indonesia \\ ${ }^{2)}$ Faculty of Agriculture, University of Brawijaya, Jl. Veteran, Malang, Indonesia \\ ${ }^{*}$ Corresponding author : erwinprastowo@gmail.com \\ Received : 11 February 2020 / Acepted : 29 February 2020
}

\begin{abstract}
Soil fertility level improvement in an environmentally friendlier way has been a key to provide a sustainable cocoa production. Earthworms, as decomposer agents in soil, may provide a sustainable way of improving soil fertility level. The objective of this study was to quantify top soil earthworm population and some important soil characteristics, e.g. soil moisture, organic $\mathrm{C}$, total $\mathrm{N}$, and $\mathrm{pH}$ to see if there was any response observed due to different level and type of organic waste applications. Their surface populations, i.e. at $5-10 \mathrm{~cm}$ depth, within cocoa circle were investigated with respect to different type of organic waste applications, i.e. cocoa pod waste, cocoa leaf waste, and sheep manure. For cocoa derived organic matter, the level of application was arranged at 5, 10, and 20 ton/ ha to obtain an optimal condition at which the highest population of earthworm is obtained. A field investigation was performed at a square of $900 \mathrm{~cm}^{2}$ sized area, and extending down to $5-10 \mathrm{~cm}$ depth. Additionally, the effect of organic waste to top soil characteristics were also determined mainly to some important parameters such as soil moisture, organic carbon, total nitrogen, and soil $\mathrm{pH}\left(\mathrm{H}_{2} \mathrm{O}\right)$. Our analysis suggest that field heterogeneity condition may limit the conclusion, mainly related to the question of to what extent the effect of organic wastes to the changes in terms of soil characteristics. The application of organic wastes was able to increase the population of earthworms. Their highest abundance was obtained following the application of cocoa pod at 20 ton/ha, which was about 5 times higher than the population in the control.
\end{abstract}

Keywords: Sustainable cocoa production, cocoa soil, earthworm, organic waste

\section{INTRODUCTION}

Sustainable cocoa production has become an urgent issue especially related to the worldwide concerns due to chemical input contributions, such as herbicide, pesticide, and inorganic fertilizers to environmental damage. This means that cocoa production allows for agronomical practices in a way that they are environmentally friendly, i.e. biotic and abiotic components. Yet they should be simple and inexpensive practices, and economically advantageous (Singh et al., 2018).
After couple of decades utilization of agrochemicals to boost crop productions, there is a need in reducing their inputs and relying on organic fertilizer as a source for crop nutrient (Whalen et al., 1998). Therefore, cocoa management strategy development that promote the use of non-chemical inputs as a means to enhance both crop and land productivity are importantly required to support the sustainable farming systems.

Crop management strategies that increase the soil microbial activity and diversity as well 
as maintain soil organic $\mathrm{C}$ level, e.g. cocoa - agroforestry system, have been widely recognized as key initiatives to support sustainable production (Jagoret et al., 2014; Fonte et al., 2019; Plaas et al., 2019). Both determinants, i.e. soil microorganisms and soil organic matter level, are strongly linked together (Hicks et al., 2019) to make up a sustainable system. Soil microbial populations, especially earthworms, have received a great attention as they provide a good indicator for crop management effect such as organic versus conventional system, tillage versus no-tillage, cropping rotation, soil cover, and fertilization (Whalen et al., 1998; Scullion et al., 2002; Pulleman et al., 2005; Fonte et al., 2009; Peigné et al., 2009; Ashworth et al., 2017).

Furthermore, earthworms are considered to improve soil fertility level through increasing the nutrient and water availability for crops, promoting soil aggregation, and enhancing stress tolerance as well as pest regulation (Cai et al., 2019; Fonte et al., 2019). Additionally, they play as a key regulator for soil organic matter dynamics in many agroecosystems (Fonte et al., 2009) through feeding activities such as burrowing, consumption and excretion that facilitate the incorporation of organic matter into the soil (Pulleman et al., 2005). Due to their strong association to soil organic matter (Whalen et al., 1998), the growing population of earthworm in the soil may be attributable to a better environmental condition. Therefore, it can be concluded that surface species of earthworm may provide a strong link to sustainable cocoa production development.

Cocoa soil fertility evaluation following the organic inputs allow for mostly crop, soil physics and chemistry parameters, and yield to be identified. As discussed earlier, however, the biotic components in the soil for instance earthworm, play a crucial role especially related to organic $\mathrm{C}$ and nutrient cycling regulations. Therefore, the present study will investigate top soil earthworm population and some important soil characteristics, e.g. soil moisture, organic $\mathrm{C}$, total $\mathrm{N}$, and $\mathrm{pH}$ to see if there is any response observed due to different level and type of organic waste application.

\section{MATERIALS AND METHODS}

\section{Research Location}

A field investigation was carried out in Kaliwining Experimental Station, Indonesian Coffee and Cocoa Research Institute, Jember, East Java. The cocoa farms are characterized by shallow water table at about 80-100 cm depth, especially during rainy seasons, situated at the toeslope of $3088 \mathrm{~m}$ high Argopuro volcano to the south with altitude about $60 \mathrm{~m}$ asl. The topography is plain with slope gradient estimated around $0-4 \%$. As situated at higher level than Bedadung river, the closest river nearby, but slightly lower than Mayang river at a more distance point, it is therefore suggested that the sediment in this area is, mostly, coming from volcanic ash derived materials.

A moderate soil development stage of volcanic materials derived Inceptisols in the area together with average of 6.82 wet months and 4.31 dry months, or climate type D (moderate) based on Schmidt-Fergusson classification has provided a moderate suitability level for cocoa production. Additionally, the cocoa farms provide a good soil fertility level with high category for mineral compositions such as $\mathrm{K}, \mathrm{Ca}, \mathrm{Mg}$, and $\mathrm{Na}$, as well as for cation exchange capacity (Erwiyono et al., 2006; Sugiyanto et al., 2008).

\section{Experimental Design}

To prepare research trials, 9 cocoa trees were selected to make up a totally 72 cocoa 
standing with allowing for 8 different organic waste treatments, i.e. blank (B0); three different application level of cocoa pod waste (plot code B1, B2, and B3) at 5, 10, and 20 ton/ha; three different application level of cocoa leaf waste (plot code B4, B5, and B6) at 5, 10, and 20 ton/ha; and sheep manure application at 20 ton/ha. The trees were selected based on some field criteria such as healthy, vigour, and demonstrating an average size of trees in the plot. This means that the outliers were not included in the observations.

The design was arranged in randomized completely block design applying 3 replications per treatments. This design was applied to reduce a possibility bias due to soil fertility gradients. The replication trees were not necessarily obtained from the same rows, yet there is a chance that they were selected from different rows depending on selection criteria. With $180 \mathrm{~m}$ x $48 \mathrm{~m}$ size of block, the lateral field heterogeneity with respect to soil morphology characteristics is supposed to be low with the same soil type representing a limited size of observation plot.

\section{Organic Waste Application}

Three different types of organic matter, i.e. cocoa pod, cocoa leaf, and sheep manure were applied on the surface of soil within the cocoa canopy circles. Additional practices were required to mix them with the top soil at about $5-10 \mathrm{~cm}$ depth carefully by a manual hoeing. They were incubated under environmental condition for about 1 month before observations. Earthworm hand-sorting collection at the soil surface were performed within the square of $30 \mathrm{~cm} \times 30 \mathrm{~cm}$ area in the cocoa canopy circle, and covering the blocked spot down into 5-10 cm depth. A further species identification was not carried out in this research.

\section{Research Observation}

Soil temperature at which the organic wastes were applied was regularly measured for one-week duration interval by, simply, inserting a soil thermometer into the top soil, and holding it for a couple of minutes until a stable measurement was obtained before recording the data.

Earthworms were collected at the end of rainy seasons between April to May 2015 . In the early of this period, the soil moisture condition was slightly high (Table 1), and air temperature was beginning to rise, hence favourable for soil macrofauna growths and activities including earthworms. During the investigation, herbicide and pesticide application were not implemented in these plots to avoid their disturbance to earthworm populations. However, in different time, they are applied as common agronomic practices. Chemical fertilizers as urea, TSP, and $\mathrm{KCl}$ have been applied before implementation the trials. Cocoa farms are regularly subject to compost application with amount of $10-20 \mathrm{~kg}$ per year per tree.

Prior to, and after cocoa waste application the mixture of top soil composite samples from $0-20 \mathrm{~cm}$ depth were taken from each treatment. The sample preparation in the laboratory includes air drying, and $\varphi<2 \mathrm{~mm}$ sieving to obtain a high homogeneity of soil sample materials, and thus facilitate the laboratory analysis. The analysis was performed to measure some selected soil parameters, i.e. soil moisture content, texture by pipette method, porosity, $\mathrm{pH}$ (1:2.5), organic $\mathrm{C}$ by Walkley and Black method, and total $\mathrm{N}$ using Kjeldahl method.

\section{Statistical Analysis}

To explore for any significant differences among multiple treatment means, the analysis 
of variance was performed with further Duncan's new multiple range test (DMRT) posthoc test running at 5\% significant level. To see if there was any relationship between quantitative parameters, a Pearson correlation were performed with $\mathrm{R}^{2}$ values ranging from 0.30 to 1.00 are assumed to be an indication for low to strong correlation. Below $\mathrm{R}^{2}$ 0.30, the correlation between parameters are negligible.

\section{RESULTS AND DISCUSSION}

The initial characteristics of soil used for trials (Table 1), mainly based on organic $\mathrm{C}$ and total $\mathrm{N}$, suggest a moderate to high level of fertility. Given that both organic $\mathrm{C}$ and total $\mathrm{N}$ are derived from organic inputs, their accumulation in the soils are likely related to agronomic practices such as manure, organic residues and compost applications. The high organic $\mathrm{C}$ content with corresponding to low $\mathrm{C} / \mathrm{N}$ ratio may indicate a high input of mineral fertilizer derived $\mathrm{N}$ such as urea. A high availability of soil $\mathrm{N}$ during the investigation may provide a high energy for microbial activities. A manual tillage practice, i.e. hoeing, in the cocoa canopy circle, as a regular agronomic operational in the early of dry seasons, may have facilitated the organic matter break up. Therefore, in this case the stable condition of soil organic matter under cocoa farming with respect to observation plots is understandable.
The soil is characterized by high sand content with concomitant the high soil moisture level (Table 1). Data suggest the significant role of organic $\mathrm{C}$ in terms of its capacity to hold soil moisture. The high abundance of sand in the point just close to cocoa standing may indicate the effect of soil mixing during planting holes preparations. In the regular protocol for cocoa agronomic practices, a typical coarser subsoil is now placed at the surface of the ground surrounding the seedling while the top ground is moved down below the rhizosphere. The depth-gradient texture variation is typical in the volcanic derived soil parent materials. In different place in the experimental station, a common high clay content is up to about $40 \%$ (Erwiyono et al., 2006; Sugiyanto et al., 2008), indicating fine particles derived parent materials.

The high moisture level of soil (Table 1) may indicate a high contribution from precipitation as during the dry period the soil moisture level may be low at about 20-25\%. The high soil acidity in the investigated plots are different from previous finding such as Erwiyono et al. (2006) and Sugiyanto et al. (2008), as their results showed a bit higher level of soil $\mathrm{pH}$ exceeding 6 . It is assumed that the low level of initial $\mathrm{pH}$ in the research plots may be the effect of annual compost application as indicated in the previous section. Additionally, long-term inorganic fertilizer applications may also responsible to the lowering soil $\mathrm{pH}$.

Table 1. Each plot soil characteristics before organic waste applications using cocoa pod, cocoa leaf waste and sheep manure/ha

\begin{tabular}{|c|c|c|c|c|c|c|c|}
\hline \multirow{2}{*}{$\begin{array}{l}\text { Treatment } \\
\text { (ton/ha) }\end{array}$} & \multirow{2}{*}{$\begin{array}{c}\text { Soil moisture } \\
(\%)\end{array}$} & \multicolumn{3}{|c|}{$\begin{array}{c}\text { Soil texture } \\
(\%)\end{array}$} & \multirow{2}{*}{$\begin{array}{c}\text { Organic C } \\
(\%)\end{array}$} & \multirow{2}{*}{$\begin{array}{l}\text { Soil } \mathrm{pH} \\
(1: 2.5)\end{array}$} & \multirow{2}{*}{ Total N (\%) } \\
\hline & & Sand & Silt & Clay & & & \\
\hline Control & 40.45 & 92.34 & 6.77 & 0.89 & 3.65 & 5.44 & 0.46 \\
\hline Cocoa pod waste (5) & 49.70 & 93.76 & 5.64 & 0.60 & 2.06 & 4.94 & 0.35 \\
\hline Cocoa pod waste (10) & 45.73 & 96.17 & 3.42 & 0.45 & 2.31 & 5.09 & 0.43 \\
\hline Cocoa pod waste (20) & 49.25 & 92.35 & 6.74 & 0.91 & 2.98 & 4.87 & 0.38 \\
\hline Cocoa leaf waste (5) & 51.98 & 94.60 & 6.93 & 0.47 & 3.81 & 4.84 & 0.53 \\
\hline Cocoa leaf waste (10) & 53.37 & 93.92 & 4.80 & 1.28 & 3.15 & 5.03 & 0.51 \\
\hline Cocoa leaf waste (20) & 46.63 & 93.12 & 5.72 & 1.16 & 5.28 & 5.05 & 0.46 \\
\hline Sheep manure (20) & 46.2 & 84.09 & 6.18 & 9.73 & 5.09 & 5.01 & 0.50 \\
\hline
\end{tabular}


Following the organic waste applications, the response of each plot treatment may vary, and there is also a case that they have not affected significantly the initial soil characteristics in the plots (Table 2). The inconsistent trend of data is observed not only among treatments but also for the same plot treatment with correspond to the initial soil characteristics. The high irregularity of data may be attributable to the small-scale variability of field conditions. As the composite samples were taken randomly from tree circle, therefore as an open system, the variation of soil samples, especially related to physics, chemistry and biology characteristics, in the context of both spatially and temporally, may lead to the difference in the absolute amounts of specific parameters.

Additionally, the decrease in soil organic $\mathrm{C}$ content after organic waste applications with corresponding to a relatively stable total $\mathrm{N}$ may have contributed to the lower $\mathrm{C} / \mathrm{N}$ ratio at about 5-6 (Table 2). Data may suggest a rapid loss of organic $\mathrm{C}$ during the incubation of organic wastes. It is assumed that acceleration of $\mathrm{CO}_{2}$ release through organic matter break up may be associated to the more intensive the microbial activities. In this paper, the comparison of earthworm's figure before and after the treatments are not able to be confirmed, yet the decrease in $\mathrm{C} / \mathrm{N}$ ratio of soil organic matter in every plot may have indicated the growing microbial populations driving the decomposition processes.
Generally, the effect of pod derived cocoa waste to organic $\mathrm{C}$, total $\mathrm{N}$, and soil moisture are better than leaf derived cocoa waste (Figure 1). The better effect of pod derived cocoa waste may be attributable to the higher organic $\mathrm{C}$ content in the cocoa pod, which was found of up to $94 \%$ (BritoVega et al., 2018). Given that total $\mathrm{N}$ is strongly associated to organic $\mathrm{C}$, as organic $\mathrm{N}$ accounts for about $90 \%$ of total $\mathrm{N}$, therefore the higher organic $\mathrm{C}$ will be assumed to provide higher total $\mathrm{N}$. However, the increase in the organic waste amounts are not necessarily connected to the increase in both organic $\mathrm{C}$ and total $\mathrm{N}$ level. Furthermore, the optimum level of organic wastes is obviously not able to be confirmed in this research.

Temperature during organic matter decompositions is around $24^{\circ} \mathrm{C}$ with highest value of up to $25.1^{\circ} \mathrm{C}$. Our finding suggests that temperature produced during decomposition is not necessarily connected to the amount of organic wastes applied, as data indicate its highest value recorded at lowest amount of organic matter applied, i.e. 5 ton cocoa leaf/ha (Table 2). For the same amount of organic wastes, the type of organic materials may be responsible more to the heat produced, i.e. cocoa leaf derived organic waste was producing higher temperature than cocoa pod derived materials during about one month decomposition.

Table 2. Soil characteristics of each plot after organic waste applications

\begin{tabular}{lcccccc}
\hline $\begin{array}{l}\text { Treatment } \\
\text { (ton/ha) }\end{array}$ & $\mathrm{T}\left({ }^{\circ} \mathrm{C}\right)$ & $\begin{array}{c}\text { Soil moisture } \\
(\%)\end{array}$ & $\begin{array}{c}\text { Soil porosity } \\
(\%)\end{array}$ & $\begin{array}{c}\text { Organic C } \\
(\%)\end{array}$ & $\begin{array}{c}\text { Soil pH } \\
(1: 2.5)\end{array}$ & $\begin{array}{c}\text { Total N } \\
(\%)\end{array}$ \\
\hline Control & $24.4 \mathrm{~b}$ & $25.86 \mathrm{a}$ & 46.10 & $2.10 \mathrm{a}$ & $4.71 \mathrm{bc}$ & $0.40 \mathrm{a}$ \\
Cocoa pod waste $(5)$ & $24.0 \mathrm{a}$ & $45.51 \mathrm{bc}$ & 50.55 & $3.26 \mathrm{c}$ & $4.45 \mathrm{ab}$ & $0.48 \mathrm{~cd}$ \\
Cocoa pod waste $(10)$ & $24.4 \mathrm{~b}$ & $48.53 \mathrm{c}$ & 48.79 & $2.59 \mathrm{abc}$ & $4.00 \mathrm{a}$ & $0.46 \mathrm{a}$ \\
Cocoa pod waste $(20)$ & $24.7 \mathrm{~cd}$ & $39.67 \mathrm{bc}$ & 49.53 & $2.77 \mathrm{abc}$ & $4.11 \mathrm{a}$ & $0.50 \mathrm{e}$ \\
Cocoa leaf waste (5) & $25.1 \mathrm{e}$ & $38.39 \mathrm{~b}$ & 55.64 & $2.46 \mathrm{ab}$ & $4.27 \mathrm{ab}$ & $0.49 \mathrm{de}$ \\
Cocoa leaf waste $(10)$ & $24.5 \mathrm{bc}$ & $29.56 \mathrm{a}$ & 51.54 & $2.08 \mathrm{a}$ & $4.22 \mathrm{a}$ & $0.41 \mathrm{a}$ \\
Cocoa leaf waste $(20)$ & $24.8 \mathrm{de}$ & $31.81 \mathrm{a}$ & 48.95 & $2.40 \mathrm{ab}$ & $5.07 \mathrm{c}$ & $0.49 \mathrm{de}$ \\
Sheep manure $(20)$ & $24.4 \mathrm{~b}$ & $40.70 \mathrm{bc}$ & 56.40 & $2.97 \mathrm{bc}$ & $4.45 \mathrm{ab}$ & $0.47 \mathrm{bcd}$ \\
\hline
\end{tabular}


Soil moisture level decrease from the initial condition may relate the switch with respect to climate seasonal condition providing a gradual increase for air temperature. It seems that the contribution of both clay and soil organic $\mathrm{C}$ content are not really signifi- cant in this sense. It is suggested that the small-scale field heterogeneity as a factor to contribute to the variation in terms of composite sample characteristics resulting in the bias conclusion to draw.
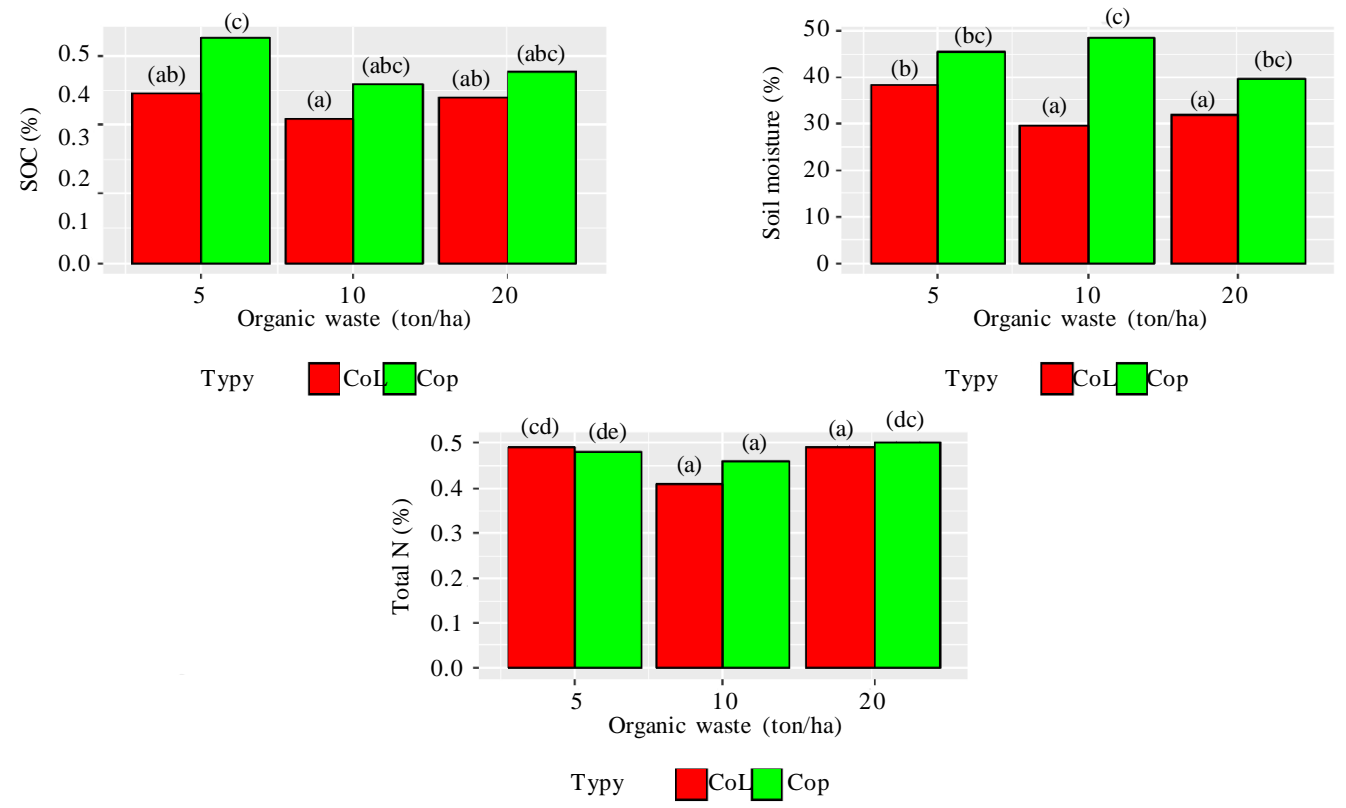

Figure 1. Effect of cocoa waste type to soil organic carbon (SOC) (\%), soil moisture (\%), and total N (\%) with $\mathrm{CoL}=$ cocoa leaf derived organic waste, and $\mathrm{CoP}=$ cocoa pod derived organic waste

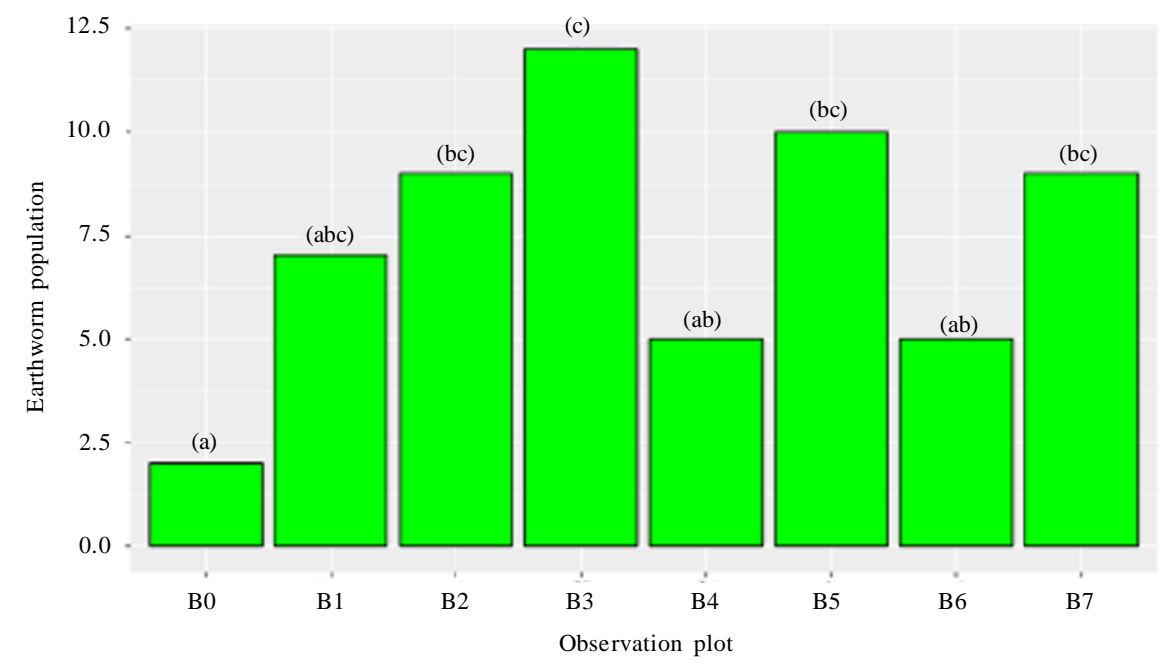

Figure 2. Earthworm population in the plots after organic waste applications. $(\mathrm{B} 0=$ control; $\mathrm{B} 1=5$ ton cocoa pod waste/ha; B2 $=10$ ton cocoa pod waste/ha; B3 $=20$ ton cocoa pod waste/ha; B4 = 5 ton cocoa leaf waste/ha; B5 $=10$ ton cocoa leaf waste/ha; B6 $=20$ ton cocoa leaf waste/ha, and $\mathrm{B} 7=20$ ton sheep manure/ha) 
The highest level of cocoa pod waste application (20 ton/ha) is, significantly, associated to the highest abundance of earthworm population observed in the plot, resulted in around 12 earthworms per $900 \mathrm{~cm}^{2}$ area (Figure 2). As the investigation was limited down only to $5-10 \mathrm{~cm}$ from soil surface, therefore epigeic earthworms (Chan, 2001), were the dominant type that existed. A further collected earthworm species name was not carried out in this research. The high abundance of earthworms suggest an indication of good soil fertility condition (Jhonson, 2009). They increase soil aeration, drainage and porosity through burrows by which the top- and subsoils are mixed (Fonte et al., 2009; Peigné et al., 2009). Additionally, they also deposit the nutrient-rich castings on the soil surface that higher than the original soils (Scullion et al., 2002), as well as plant growth stimulant (Jhonson, 2009).

A corresponding amount for cocoa leaf waste did not give the same effect pointing out the importance of organic matter types to the earthworm population in the top soil. Conversely, at the lower amount of cocoa waste application, i.e. 10 ton/ha, for both pod and leaf derived organic matter do not affect differently with respect to earthworm population. They provide insignificantly different effect with higher level of sheep manure derived organic waste.

In this research, it is clear that the application of organic waste is able to increase the number of earthworm population in the soil surface (Figure 2). While the total earthworm populations observed in the control is about 2 from a $90 \mathrm{~cm}^{2}$ sized investigation plot, the addition of organic wastes have increased more than doubled in terms of their populations. As earthworm positive effect to the soil fertility level has been suggested through many papers globally (Whalen et al., 1998; Scullion et al., 2002; Pulleman et al., 2005; Fonte et al., 2009; Peigné et al., 2009; Asworth et al.,
2017), their existence in the top soil is obviously required especially in order to achieve a sustainable yield of cocoa farm.

Table 3. Coefficient correlation among observation variables $($ Temp $=$ soil temperature; $\mathrm{SM}=$ soil moisture; $\mathrm{SOC}=$ soil organic $\mathrm{C} ; \mathrm{pH}=$ soil acidity; $\mathrm{TN}=$ total $\mathrm{N}$ ).

\begin{tabular}{lccccc}
\hline & Temp & SM & SOC & pH & T N \\
\hline Temp & & & & & \\
SM & -0.16 & & & & \\
SOC & -0.46 & 0.70 & & & \\
pH & 0.11 & -0.64 & -0.17 & & \\
TN & 0.22 & 0.79 & 0.71 & -0.37 & \\
Worm & -0.10 & 0.58 & 0.40 & -0.67 & 0.47 \\
\hline
\end{tabular}

However, data analysis demonstrates a negative correlation between earthworm population and soil $\mathrm{pH}$ (Table 3 ), which means that to some extent the lower level of soil $\mathrm{pH}$ may explain for the higher number of earthworm population in the top soil. Data also suggest that their population in the soil may also take into account different key factors such as soil moisture status, soil $\mathrm{pH}$, organic $\mathrm{C}$, and total $\mathrm{N}$ (Table 3 ), as their $\mathrm{R}^{2}$ values indicate low to moderate correlations. Soil organic matter has been suggested to provide both nutrient-rich substrate and colonized-microorganisms for earthworms (Whalen et al., 1998). Additionally, the strong connection of earthworm populations to high soil moisture condition and close-to-neutral $\mathrm{pH}$ level, may have confirmed the former finding (Jhonson, 2009).

\section{CONCLUSIONS}

Organic waste application effects to soil characteristics is not really clear attributable to the small-scale field heterogeneity condition of plots. A bias information provided through composite samples may have led to an insignificant difference for results obtained between control and some organic waste treated plots. The application of organic wastes has indicated to improve number of earthworm populations of up to 5 times higher than control plot, which may depend 
also on the type of organic matter sources. This finding suggests that additional factors may have played an important role with respect to earthworm existence in the top soil such as soil moisture status, organic $\mathrm{C}$, total $\mathrm{N}$, and level of soil acidity.

\section{ACKNOWLEDGEMENT}

We thank Dr. John Bako Baon for his support and helpful comments during research and manuscript preparations.

\section{REFERENCES}

Ashworth, A.J.; F.L. Allen; D.D. Tyler; D.H. Pote \& M.J. Shipitalo (2017). Earthworm populations are affected from longterm crop sequences and bio-covers under no-tillage. Pedobiologia, 60, 27-33.

Brito-Vega, H.; J.M. Salaya-Domínguez; E. GómezMéndéz; A. Gómez-Vázquez \& J.B. AnteleGómez (2018). Physico-chemical properties of soil and pods (Theobroma cacao L.) in cocoa agroforestry systems. Journal of Agronomy, 17, 48-55.

Cai, S.; J. Wang; W.Lv; S. Xu \& H. Zhu (2019). Nitrogen fertilization alters the effects of earthworms on soil physicochemical properties and bacterial community structure. Applied Soil Ecology, In Press.

Chan, K.Y. (2001). An overview of some tillage impacts on earthworm population abundance and diversity - implications for functioning in soils. Soil Tillage \& Research, 57, 179-191.

Erwiyono, R.; A.A. Sucahyo; Suyono \& S. Winarso (2006). The effectiveness of foliar application of potassium on flowering and fruiting of cocoa. Pelita Perkebunan, $22,13-24$.

Fonte, S.J.; C. Bontero; D.C. Quintero; P. Lavelle \& C. van Kessel (2019). Earthworm regulate plant productivity and the efficacy of soil fertility amendments in acid soils of the Colombian Llanos. Soil Biology and Biochemistry, 129, 136-143.
Fonte, S.J.; T. Winsome \& J. Six (2009). Earthworm populations in relation to soil organic matter dynamics and management in California tomato cropping systems. Applied Soil Ecology, 41, 206-214.

Hicks, L.C.; P. Meier; A.T. Nottingham; D.S. Reay; A.W. Stott; N. Salinas \& J. Whitaker (2019). Carbon and nitrogen inputs differentially affect priming of soil organic matter in tropical lowland and montane soils. Soil Biology and Biochemistry, 129, 212-222.

Jagoret, P.; O. Deheuvels \& P. Bastide (2014). Sustainable cocoa production. Learning from agroforestry. Perspective, 27, 1-4.

Jhonson, C. (2009). Biology of Soil Science. Oxford Book Company. Jaipur, India.

Lavelle, P. (1998). Earthworm activities and the soil system. Biology and Fertility of Soils, 6, $237-251$.

Peigné, J.; M. Cannavaciuolo; Y. Gautronneau; A. Aveline; J.L. Giteau \& D. Cluzeau (2009). Earthworm populations under different tillage systems in organic farming. Soil \& Tillage Research, 104, 207-214.

Plaas, E.; F. Meyer-Wolfarth; M. Banse; J. Bengtsson; H. Bergmann; J. Faber; M. Potthoff; T. Runge; S. Schrader \& A. Taylor (2019). Towards valuation of biodiversity in agricultural soils: A case for earthworms. Ecological economics, 159, 291-300.

Pulleman, M.M.; J. Six; A. Uyl; J.C.Y. Marinissen \& A.G. Jongmans (2005). Earthworms and management affect organic matter incorporation and microaggregate formation in agricultural soils. Applied Soil Ecology, 29, 1-15.

Scullion, J.S.; S. Neale \& L. Philipps (2002). Comparisons of earthworm populations and cast properties in conventional and organic arable rotations. Soil Use and Management, 18, 293-300.

Singh, J.; S. Singh; A.P. Vig; S.A. Bhat; S.S. Hundal; R. Yin \& M. Schädler (2018). Conventional farming reduces the activity of earthworms: Assessment of genotoxicity test of soil and vermicast. Agriculture and Natural Resources, 52, 366-370. 
Sugiyanto.; J.B. Baon \& K.A. Wijaya (2008). Soil chemical properties and nutrient uptake of cocoa as affected by application of different organic matters and phosphate fertilizers. Pelita Perkebunan, 24, 188-204.
Whalen, J.K.; R.W. Parmelee \& C.A. Edwards (1998). Population dynamics of earthworm communities in corn agroecosystems receiving organic or inorganic fertilizer amendments. Biology and Fertility of Soils, 27, 400-407.

$* * 0 * *$ 